\title{
The effect of queen insemination volume on the growth of newly established honey bee (Apis mellifera) colonies
}

\author{
Alexandria N. PAYNe, Juliana RANGEL \\ Department of Entomology, Texas A\&M University, 2475 TAMU, College Station, TX 77843-2475, USA
}

Received 14 December 2017 - Revised 24 April 2018 - Accepted 20 July 2018

\begin{abstract}
The number of female progeny that a honey bee (Apis mellifera) queen produces in her lifetime is directly dependent on the amount of semen she collects upon mating (i.e., insemination volume) and the number of viable sperm cells contained within the semen (i.e., sperm viability). Queen insemination volume has been shown to alter queen mandibular pheromone profiles, as well as worker behavior and physiology at the individual level. In order to determine if queen insemination volume has any colony-level effects, we compared the growth of newly established colonies headed by queens instrumentally inseminated with either a low volume $(1.5 \mu \mathrm{L})$ or a high volume $(9.0 \mu \mathrm{L})$ of pooled semen from May to October in 2013 and 2015. We did not find a significant effect of queen insemination volume on the production of worker comb, drone comb, stored food, worker population, or seasonal queen or colony survivorship. Therefore, we concluded that queen insemination volume does not seem to directly affect growth at the colony level, at least during a colony's first year.
\end{abstract}

\section{Apis mellifera / colony growth / instrumental insemination / queen insemination volume}

\section{INTRODUCTION}

Honey bee (Apis mellifera) colonies consist of up to 50,000 female workers, a few thousand seasonal drones, and a single reproductive queen that produces all the individuals in the colony (Winston 1987). Virgin queens mate with an average of 12 to 14 drones from a variety of colonies (Tarpy and Nielsen 2002; Tarpy et al. 2004; Amiri et al. 2017), but store less than 10\% of the semen that they receive during copulation (Koeniger 1986), with only an estimated 3\% (about 4 to 7 million) of the live sperm cells received upon mating actively migrating to the queen's spermatheca for long-term storage (Harbo 1986; Wilde 1994; Collins 2000; Baer 2005; Cobey 2007). This amounts to about 8 to $12 \mu \mathrm{L}$ of semen (Mackensen 1964; Woyke

Corresponding author: J. Rangel, jrangel@tamu.edu Manuscript editor: David Tarpy
1989; Cobey 2007), which the queen uses over time to fertilize up to 1500 to 2000 workerdestined eggs daily (Winston 1987). If a queen's stored sperm is depleted prematurely, or if the sperm is unviable, she can only lay unfertilized eggs, turning into a "drone layer" that stops producing workers. This halt in worker production disrupts colony population maintenance and growth (Seeley 1995). Therefore, because the queen is the only female within a colony that can produce fertilized eggs, a colony's productivity is directly linked to its queen's reproductive capacity (Rangel et al. 2013).

Queen insemination volume has been demonstrated to impact a number of physiological and behavioral traits in queens and workers including queen mandibular gland chemical profiles (Richard et al. 2007), queen retinue size (Richard et al. 2007; Kocher et al. 2009; Niño et al. 2012), Dufour's gland chemical profile (Richard et al. 2011), vitellogenin protein titers (Kocher et al. 2009), and queen and worker gene expression in the brain (Richard et al. 2007; 
Kocher et al. 2008, 2009, 2010; Niño et al. 2013). Most of these studies have relied on instrumental insemination techniques to carefully control the number and genetic strain of drones supplying semen to the queen. Richard et al. (2007) instrumentally inseminated virgin queens either with the semen from one drone (i.e., single-drone inseminated, or "SDI") and thus, with low semen volume, or with pooled semen from ten drones (i.e., multiple-drone inseminated, or "MDI") and thus, with high semen volume. They found that insemination volume affected the expression of certain genes in the brain and altered the chemical profiles of queen mandibular gland contents. They also suggested that differences in the chemical profile of the mandibular glands were perceived by workers, as the authors counted more bees in the retinue around MDI queens compared to SDI queens in observation hive experiments. They also performed cage studies to show that workers were more attracted to the extracts of mandibular gland contents from MDI queens as opposed to SDI queens.

A similar study by Richard et al. (2011) looked at the effect of instrumental insemination and insemination volume on the chemical profile of queen Dufour's glands and the expression of vitellogenin. The authors found significant differences between SDI and MDI queens in the relative abundance of most chemicals produced by the Dufour's glands, particularly esters. Using cage bioassays, they found that workers were more attracted to Dufour's gland extracts obtained from SDI compared to those from MDI or virgin queens. They also found that vitellogenin gene expression was higher in virgin queens compared to inseminated queens, and was higher in MDI than in SDI queens.

Despite these interesting results, instrumental insemination, as used in the aforementioned studies, can alter queen physiology when compared to the amount and type of semen a queen can collect from mating naturally with multiple drones. Only two studies have looked at how inseminating queens with either a low or high volume of semen from a pool of drones (not SDI vs. MDI queens) affects worker and queen behavior and physiology. In one of these studies, queens were instrumentally inseminated with either $1.5 \mu \mathrm{L}$ or $8.0 \mu \mathrm{L}$ of semen from a pool of around 150 drones from different colonies (Niño et al. 2012). When the queens were placed into observation hives, the authors found a significantly higher number of workers in the retinue around high-volume queens compared to low-volume queens. However, they did not find any statistical differences between queen types when comparing the chemical composition of the Dufour's glands or the amount of juvenile hormone or methyl farnesoate in the hemolymph of workers exposed for seven days to either high- versus low-inseminated queens. In the second study, queens were instrumentally inseminated with either $1.5 \mu \mathrm{L}$ or $8.0 \mu \mathrm{L}$ of semen from a pool drones and found that insemination volume triggers post-mating changes in molecular pathways involved in reproduction (Niño et al. 2013).

Unlike previous studies, which looked at changes in physiology and behavior at an individual level, we wanted to determine whether queen insemination volume has effects at the colony level. In this study, we explored whether queen insemination volume affects the growth and seasonal survival of newly established colonies. We did so by instrumentally inseminating queens with either $1.5 \mu \mathrm{L}$ or $9.0 \mu \mathrm{L}$ of semen from a pool of drones from different colonies. We compared the amount of comb built, brood produced, and food stored, as well as the adult population and seasonal queen survival between colonies headed by low- or high-volume inseminated queens. Understanding how low and high insemination volumes impact the growth of newly established colonies over time could help us both establish a threshold for the insemination volume needed to maintain high genetic diversity, and better optimize the productivity of colonies headed by instrumentally inseminated queens.

\section{MATERIAL AND METHODS}

\subsection{Study site and semen collection}

This study was conducted at the Janice and John G. Thomas Honey Bee Facility located at the RELLIS campus of Texas A\&M University $\left(30^{\circ} 38^{\prime} 3.60^{\prime \prime} \mathrm{N}, 96^{\circ} 27^{\prime} 56.83^{\prime \prime} \mathrm{W}\right)$ in Bryan, TX, from May to October in 2013 and in 2015. All bees used in this study were reared at this facility. 
Sexually mature drones were collected at random from ten colonies within the research apiary the day prior to the instrumental insemination procedure. The drones were kept in cages constructed from queen excluder material, and they were placed inside a bank colony so that they could be fed and tended to by worker bees until the drones were sacrificed for semen collection. When we were ready to collect the ejaculates, we removed the cages from within colonies and released the drones into an insect collection cage (Bioquip®). Semen was collected into a $100-\mu \mathrm{L}$ capillary tube following standard procedures (Cobey et al. 2013). Once the capillary tube was full, the semen was placed in an Eppendorf tube and was mixed thoroughly before being reabsorbed into the capillary to create a homogeneous sample. This procedure was repeated until we had approximately $200 \mu \mathrm{L}$ of mixed semen collected in three different capillary tubes.

\subsection{Instrumental insemination of queens}

All experimental queens were half sisters to minimize the potential effects of between-queen genetic variation. Queens were grafted from the same source colony and were subsequently raised following standard queen rearing procedures (Laidlaw and Page 1997). About five to seven days post emergence, virgin queens were instrumentally inseminated using standard techniques (Cobey 2007; Cobey et al. 2013). This procedure was chosen over natural mating to accurately measure the volume of semen received by each queen post insemination.

In total, 17 queens were used in 2013 and 19 queens were used in 2015. Virgin queens were separated into two experimental groups whereby nearly half of the queens were inseminated with $1.5 \mu \mathrm{L}$ of semen (henceforth referred to as "lowvolume" queens) and the rest were inseminated with $9.0 \mu \mathrm{L}$ of semen (henceforth referred to as "high-volume" queens). To keep track of queen mortality or replacement (i.e., supersedure) events, low-volume queens were marked with a red paint dot on the thorax, while high-volume queens were marked with a white paint dot on the thorax. In addition, all queens had one wing clipped for identification in case the paint came off. After the instrumental insemination procedure, all experimental queens were placed in individual cages and introduced into a queen bank until they were placed into experimental colonies.

\subsection{Establishment of new colonies}

New colonies were set up following a previously outlined protocol (Rangel and Seeley 2012, Rangel et al. 2013, Rangel and Tarpy 2016). First, packages of bees were created from larger, unrelated source colonies. Each package was standardized to contain $2 \mathrm{lbs}$ of bees, or approximately 6984 individuals (Mitchell 1970). The bees were shaken into a standard box $(15 \mathrm{~cm} \times 25 \mathrm{~cm} \times 35 \mathrm{~cm})$ as described by Seeley and Visscher (2003) along with a caged, previously inseminated queen. All packages were fed ad libitum with a 50:50 w/v sucrose solution for two days so that the bees reached the natural inclination of wax production for new colony founding (Seeley 1995).

After two days, the queenright packages were taken to the Janice and John G. Thomas Honey Bee Facility. Each package box was opened, the queen cage removed, and the bees shaken into a five-frame hive body. Hives were placed in alternating order at the facility based on experimental queen type to ensure similar environmental conditions for all colonies. Each hive contained five empty frames of alternating full and partial wax foundation. Full wax foundation allowed for the production of worker comb (and consequently worker brood) only, while partial wax foundations gave workers the choice of building either worker or drone comb depending on the colony's needs. Additional frames and hive bodies were added throughout the experiment to any colony whose comb production extended to all existing frames.

A total of 17 experimental colonies were set up on 13 May 2013 (sampling day 0). Of these, eight were headed by low-volume queens and nine were headed by high-volume queens. The queens were released from their cages two to three days later, once it appeared that they had been accepted by the workers. This was done by confirming that once released, the queens were not attacked by the workers surrounding them. Likewise, a total of 19 colonies were set up in 2015, ten of which were headed by low-volume queens, while nine were 
headed by high-volume queens. Unlike 2013, there were two different set up dates in 2015; ten colonies were set up on 13 May 2015 (sampling day 0 for this set of colonies) and nine colonies were set up on 8 June 2015 (sampling day 0 for this set of colonies), with a nearly equal number of low- and high-volume queens for each set up date.

\subsection{Colony growth measurements}

To test the effect of queen insemination volume on colony growth for each sampling day (starting on sampling day 1), we estimated the total combined amount of newly constructed worker and drone comb, the total combined amount of sealed worker and drone brood produced, and the total combined amount of honey, nectar, and pollen stored. To do this, we used a gridded, wooden frame that consisted of 1361 in. $\times 1$ in. squares to count the total area occupied by each parameter on both sides of each frame, as described previously (Rangel et al. 2013). Colonies set up in 2013 were sampled every three to 4 weeks from 13 May to 11 October (sampling day 5) for a total of five sampling periods after the set up date. Colonies set up in 2015 were sampled every 2 to 3 weeks through 16 October (sampling day 9) for a total of nine sampling periods. Given that we had two set up dates in 2015, the sampling was staggered so that each sampling day for each set of colonies was done every 2 to 3 weeks. For example, sampling day 1 for set 1 was done on 4 June, while sampling day 1 for set 2 was done on 22 June.

Additionally, as we became curious about patterns of worker population growth, we estimated worker population size in 2015 every 3 to 4 weeks for a total of six sampling periods: 4 June, 1 July, 29 July, 27 August, 11 September, and 5 October. Using the gridded frame, we uniformly counted the number of bees in 20 predetermined, 1 in. $\times 1$ in. squares on one side of a frame. We then extrapolated this number in order to estimate the total number of bees present on that side of the frame (136 in. $\left.{ }^{2}\right)$. This same process was carried out for the other side so that the two resulting estimates could be added together to get the estimated total adult population of that entire frame. Once this process had been repeated for all frames within a hive, the extrapolated population estimates for each frame were added together to obtain the estimated total adult population of the entire colony.

The presence of the original experimental queens was checked in each colony during every sampling period. Seasonal queen survivorship was assessed through the last sampling period in both years. If an experimental queen was deemed dead or superseded, the colony was removed from the experiment and queen mortality was recorded on that date.

\subsection{Statistical analysis}

To test the effect of queen insemination volume on colony growth, we performed a repeated measures analysis of variance (ANOVA) test for each colony growth parameter for 2013 and 2015 (Littell et al. 1998). Because the measurements of growth were taken from the same colonies over time, the model was built to test the main effects of queen insemination volume, the sampling day, and their interaction on colony growth. For all parameters measured, the interaction effects of insemination volume and sampling day were not significant. Therefore, we did not conduct pairwise tests of mean values for any colony growth parameter (Littell et al. 1998).

To test the effects of insemination volume on seasonal queen survivorship, we conducted a nonparametric Kaplan-Meier survival analysis for both experimental years (Goel et al. 2010). All tests were performed using the statistical software JMP® 12.0 (SAS Inc., Cary, NC). We set the level of statistical significance at $\alpha=0.05$ for all tests and reported all descriptive statistics as means \pm standard errors of the mean (S.E.M.).

\section{RESULTS}

We did not find any significant differences in 2013 between colonies headed by low- and highvolume queens for either the total amount of newly constructed comb $\left(F_{1,16}=2.84, P=0.11\right)$, the total amount of sealed worker and drone brood produced $\left(F_{1,16}=3.39, P=0.08\right)$, or the total amount of food stored $\left(F_{1,20}=3.47, P=0.08\right)$. There was a significant effect of the sampling day 
on the total amount of sealed brood $\left(F_{4,64}=\right.$ 14.72, $P<0.0001)$ and food stored $\left(F_{4,34}=\right.$ $4.33, P=0.006$ ), but no interaction effect between queen insemination volume and the sampling day (see Table I for all statistical values).

By the fifth and last sampling day in 2013, the total amount of comb built was $9545 \pm 921 \mathrm{~cm}^{2}$ in colonies headed by low-volume queens and 8911 $\pm 336 \mathrm{~cm}^{2}$ in those headed by high-volume queens (Figure 1a). The total amount of sealed brood was highest on the second sampling day. By the end of the experiment, there were $1703 \pm$ $852 \mathrm{~cm}^{2}$ of sealed brood in colonies headed by low-volume queens and $1994 \pm 110 \mathrm{~cm}^{2}$ in those headed by high-volume queens (Figure 1b). By the fifth sampling day, colonies headed by lowvolume queens had $1235 \pm 334 \mathrm{~cm}^{2}$ of stored food while those headed by high-volume queens had $2881 \pm 216 \mathrm{~cm}^{2}$, more than double the amount of the low-volume queen colonies (Figure 1c). None of these differences were statistically significant in the repeated measures ANOVA, however.

In 2015, we did not find any significant effect of queen insemination volume on either the total amount of newly constructed comb $\left(F_{1,18}=0.43\right.$, $P=0.52)$, the total amount of sealed worker and drone brood produced $\left(F_{1,17}=1.10, P=0.31\right)$, or the total amount of food stored $\left(F_{1,19}=0.01, P=\right.$ 0.92 ). Furthermore, there was no significant difference in the estimated adult bee population between treatment groups $\left(F_{1,19}=0.99, P=0.33\right)$. There was, however, a significant effect of the sampling day on all measures of colony growth and adult population $(P<0.0001)$, but there was no interaction effect between queen insemination volume and sampling day (Table I).

By the ninth and last sampling day in 2015, the total amount of comb built was $9787 \pm 612 \mathrm{~cm}^{2}$ in colonies headed by low-volume queens and 8984 $\pm 899 \mathrm{~cm}^{2}$ in those headed by high-volume queens (Figure 2a). The total amount of sealed brood was highest for colonies headed by highvolume queens on the third sampling day and was highest on the fifth sampling day for those headed by low-volume queens (Figure 2b). By the end of the experiment there were $1101 \pm 92 \mathrm{~cm}^{2}$ of sealed brood in colonies headed by low-volume queens and $1043 \pm 147 \mathrm{~cm}^{2}$ in those headed by highvolume queens (Figure 2b). Colonies headed by low-volume queens stored a maximum of $3710 \pm$ $693 \mathrm{~cm}^{2}$ of food compared to $3116 \pm 188 \mathrm{~cm}^{2}$ stored by those headed by high-volume queens (Figure 2c). The estimated adult population was $13,630 \pm 1663$ bees in colonies headed by lowvolume queens and 16,942 \pm 1966 bees in those headed by high-volume queens by the end of the sixth sampling day (Figure 3). None of these differences were statistically significant, however.

Lastly, queen insemination volume did not affect seasonal queen survival in newly established colonies. Of the initial 17 experimental queens reared in 2013, only two of the eight lowvolume queens $(25 \%)$ and five of the nine highvolume queens $(55 \%)$ survived through October. Despite the trend of higher survival in highvolume queens, these differences were not significantly different $\left(\chi^{2}=2.09, P=0.15\right.$; Figure 4a). Likewise, of the 19 experimental queens reared in 2015 , four of the ten low-volume queens $(40 \%)$ and six of the nine high-volume queens $(67 \%)$ survived through October, but these differences in queen survival were not statistically significant $\left(\chi^{2}=1.65, P=0.20\right.$; Figure $\left.4 b\right)$. In both years, most of the experimental queens died and only a few were superseded. Colonies whose experimental queen died were removed from the study and no longer sampled from, regardless of whether or not they were superseded.

\section{DISCUSSION}

In this study, we wanted to determine whether the volume of mixed semen that honey bee queens receive during insemination affects the productivity and seasonal survival of newly established colonies. We did so by comparing the growth of new colonies headed by either high-volume queens (i.e., those inseminated with $9 \mu \mathrm{L}$ of semen) or low-volume queens (i.e., those inseminated with $1.5 \mu \mathrm{L}$ of semen). We did not find significant effects of queen insemination volume on any of the colony growth parameters measured (i.e., worker and drone comb, worker and drone capped brood, food stored, and adult bee population) between the two colony types. Although a higher number of colonies led by high-volume queens survived throughout the duration of the study in 
The effect of queen insemination volume on the growth of newly established honey bee (Apis mellifera) colonies 599
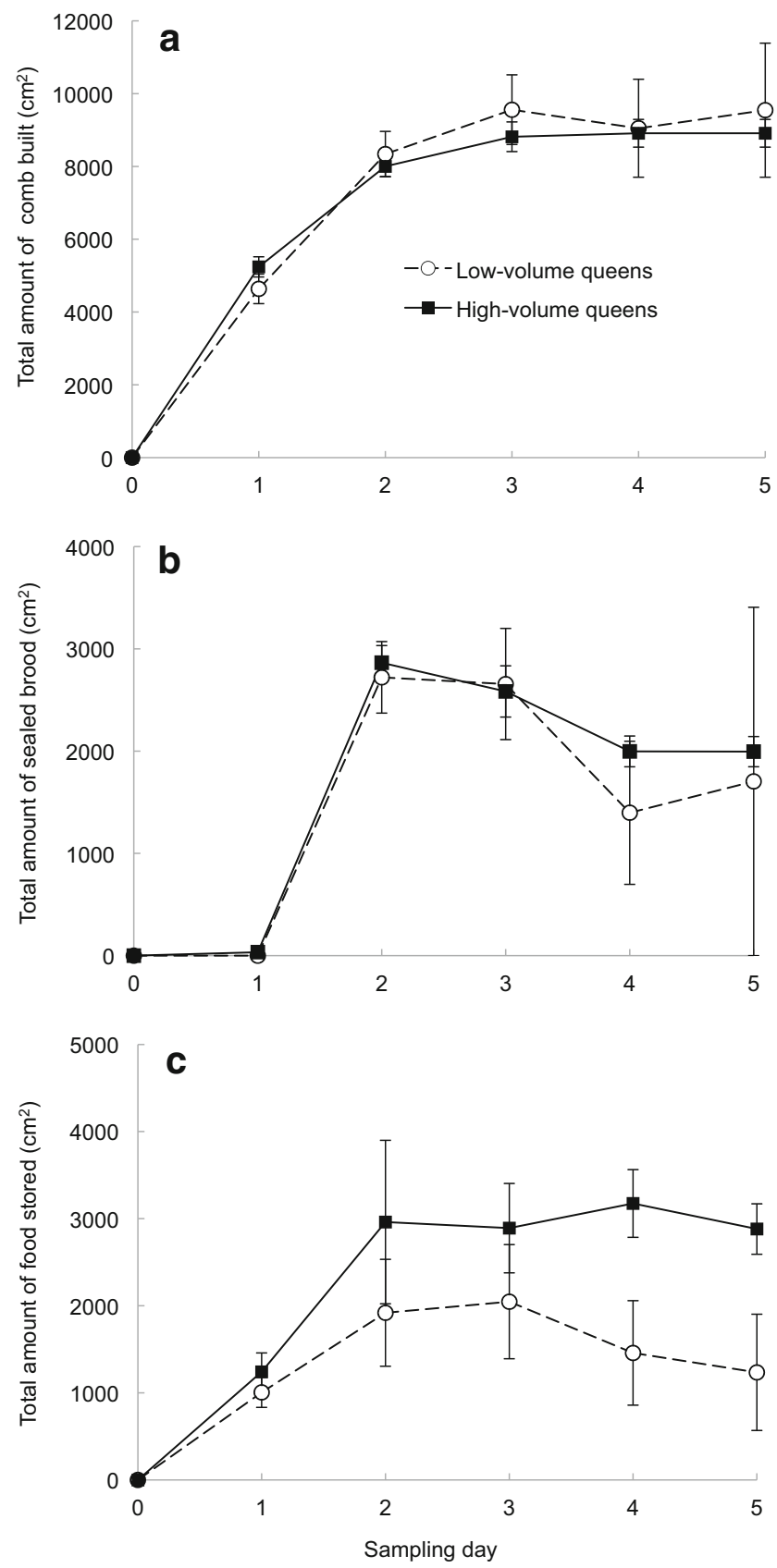

Figure 1. a-c Growth patterns for new honey bee colonies established in 2013. Eight colonies were headed by queens inseminated with $1.5 \mu \mathrm{L}$ of mixed semen (i.e., low-volume queens) and nine colonies were headed by queens inseminated with $9.0 \mu \mathrm{L}$ of mixed semen (i.e., high-volume queens). All colonies were established on 13 May (sampling day 0) and were sampled five times through 11 October 2013 (sampling day 5). Each colony was started with an artificial swarm containing $2 \mathrm{lbs}$ of bees. Data are presented as the mean \pm S.E.M. 


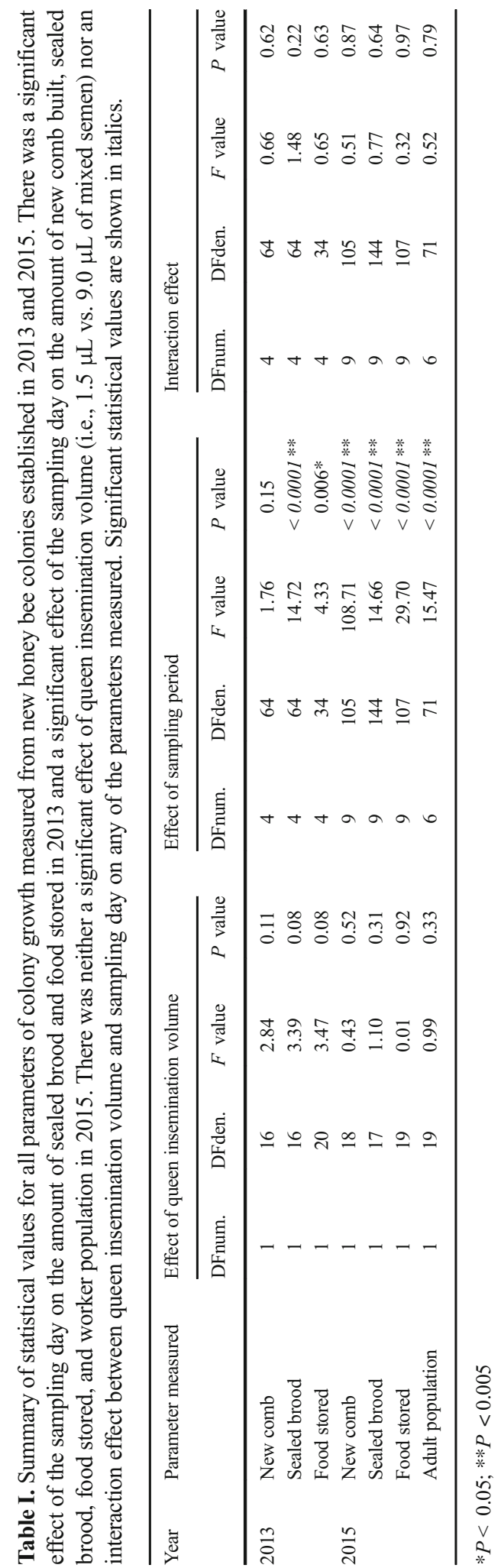

both 2013 and 2015, these differences were not statistically significant.

Even though we did not find significant differences at the colony level, queen insemination volume and quantity has been shown to alter several aspects of worker and queen physiology and behavior at the individual level, including queen mandibular and Dufour's gland chemical profiles, vitellogenin gene expression, queen retinue size, and gene expression in workers and queens (Richard et al. 2007; Kocher et al. 2008, 2009, 2010; Richard et al. 2011; Niño et al. 2012, 2013). However, in most of these studies (except for Niño et al. 2012 and Niño et al. 2013), the queens used were inseminated with semen from either one or multiple drones, not from the same pool of mixed semen at varying volumes, as done in our study.

The use of SDI and MDI queens does not separate the effects of semen volume and sperm quantity from the effects of genetic diversity conferred from multiple mating. Honey bee queens rarely mate with only one or a handful of drones. Instead, they mate with an average of 12 to 14 drones from a variety of colonies (Tarpy and Nielsen 2002; Tarpy et al. 2004), which confers high levels of genetic diversity to their progeny. For instance, high queen mating frequency, and thus high intra-colonial genetic diversity, increases a colony's ability to combat disease (Tarpy 2003; Tarpy and Seeley 2006) and improves colony productivity and survival (Mattila and Seeley 2007; Oldroyd and Fewell 2007; Seeley and Tarpy 2007).

Only two studies to date have used similar methods as ours to look at the effects of queen insemination volume on worker and queen behavior and physiology. Niño et al. (2012) tested the differences in brood production and queen survivorship in the summer between colonies headed by queens inseminated with either $1.0 \mu \mathrm{L}$ or $8.0 \mu \mathrm{L}$ of semen. Unlike the previous studies with SDI and MDI queens, Niño et al. (2012) used mixed semen from a pool of drones to inseminate experimental queens, thus eliminating the constraints derived from using semen from only one male. Interestingly, our study found similar trends in some of the parameters measured in their study, including queen survival and amount 

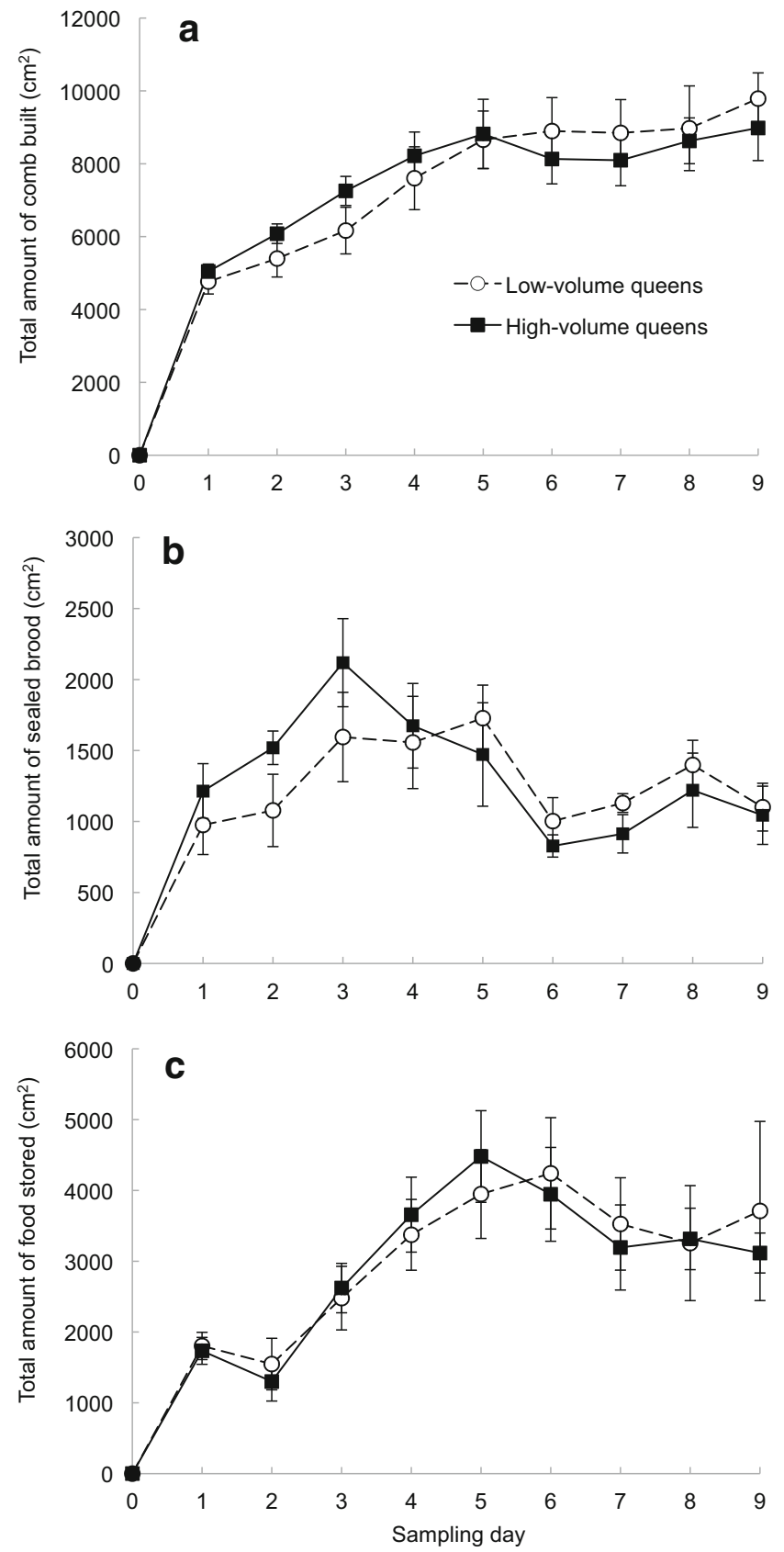

Figure 2. a-c Growth patterns for new honey colonies established in 2015 that were headed by queens inseminated with either $1.5 \mu \mathrm{L}$ of mixed semen (i.e., low-volume queens) or with $9.0 \mu \mathrm{L}$ of mixed semen (i.e., high-volume queens). Ten colonies (five headed by low-volume queens and five headed by high-volume queens) were established on 13 May (sampling day 0 for this set of colonies) and nine colonies (five headed by low-volume queens and four headed by high-volume queens) were established on 8 June (sampling day 0 for this set of colonies). All colonies were sampled every 2 to 3 weeks through 16 October (sampling day 9) for a total of nine times. Each colony was started with an artificial swarm containing $2 \mathrm{lbs}$ of bees. Data are presented as the mean \pm S.E.M. 


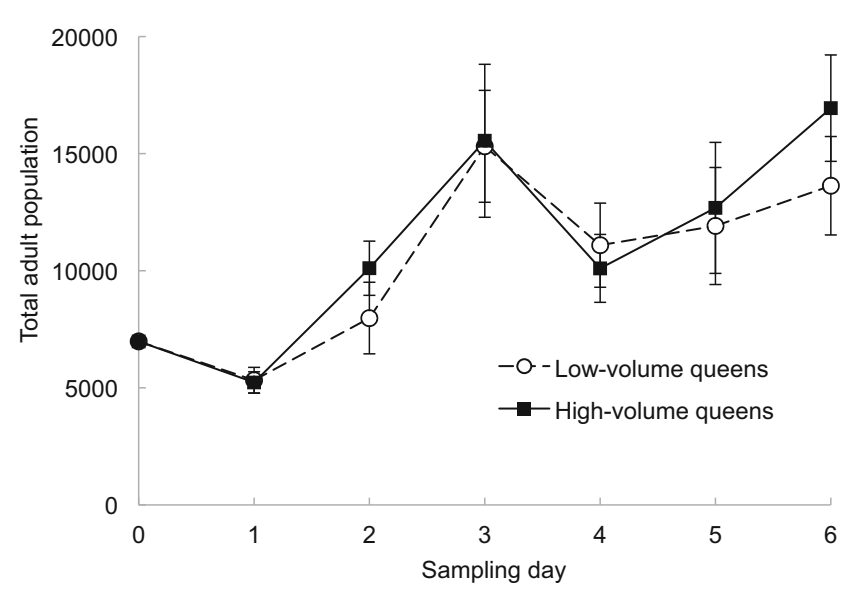

Figure 3. Estimated adult population of new honey colonies established in 2015 . Nine colonies were headed by queens inseminated with $1.5 \mu \mathrm{L}$ of mixed semen (i.e., low-volume queens) and ten colonies were headed by queens inseminated with $9.0 \mu \mathrm{L}$ of mixed semen (i.e., high-volume queens). Each colony was started with an artificial swarm containing $2 \mathrm{lbs}$ of adult workers, or approximately 6984 individuals on sampling day 0. Population size was estimated on a biweekly basis through 16 October for a total of six times. Data are presented as the mean \pm S.E.M.

of brood produced. Niño et al. (2012) found a trend in more queen cups being built in colonies headed by queens inseminated with low semen volume compared to those inseminated with high semen volume. We observed a similar (albeit not statistically significant) trend of higher queen supersedure, and thus potentially higher production of queen cells (although we did not measure this directly), in colonies headed by low-volume queens. Similarly, Niño et al. (2012) found no differences in queen survival or brood area produced between colonies headed by either queen type. This suggests that, while keeping genetic diversity constant, the volume of semen used for queen insemination does not seem to impact brood production or queen survivorship, at least during a colony's first season following its establishment.

It is possible that other variables such as weather patterns and queen nutrition, size, and/or pathogen loads could have impacted our results. When we compared the monthly average rainfall between 2013 and 2015, we found that average precipitation was higher at the onset of the experiment in 2015 compared to 2013. This higher average rainfall could have resulted in the availability of more nectar and pollen for experimental colonies and could explain why the total amount of food stored in 2015 was almost double the amount stored in
2013 by the last sampling day. However, despite the higher precipitation level at the onset of the experiment in 2015, we did not find any significant differences between 2013 and 2015 when comparing all the monthly precipitation and mean temperatures. Moreover, while we did not standardize the size of the queens used for insemination, previous studies have shown that differences in body mass at emergence is correlated with spermatheca volume (De Souza et al. 2013), which could lead to small queens harboring fewer spermatozoa in the spermatheca compared to larger queens. However, given that we did not find significantly higher rates of supersedure in low- versus high-volume queens, it seems unlikely that spermathecal size influences colony growth during a colony's first months post establishment. Finally, pathogen transmission could have occurred through the insemination process and could have affected overall queen survivorship, as 10 of the 17 experimental queens used in 2013 and nine of the 19 queens used in 2015 died during the course of the experiment. Deformed wing virus can be transmitted venereally (De Miranda and Fries 2008) and thus could have been passed from drone semen to queens during the insemination process. We did not measure pathogen loads in any of the experimental drones or queens, however, so this hypothesis remains to be tested. 


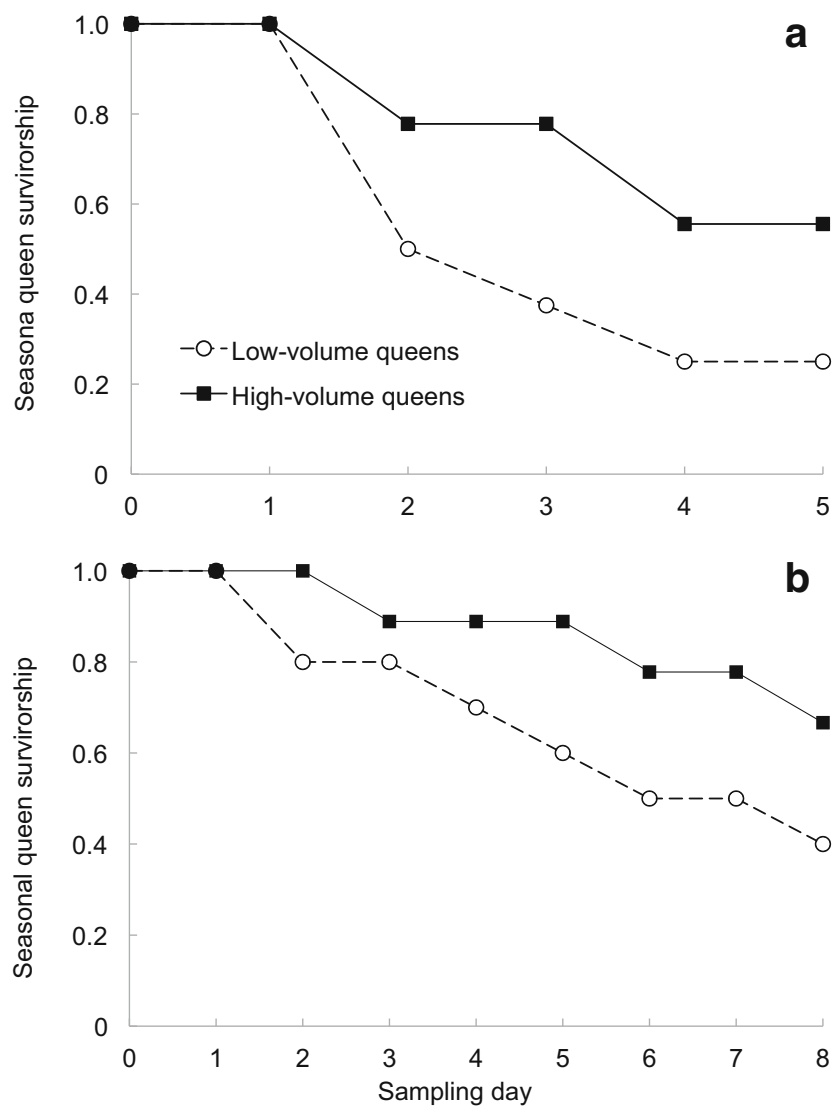

Figure 4. Seasonal queen survivorship curves in a 2013 and b 2015 for honey bee colonies headed by queens inseminated with either $1.5 \mu \mathrm{L}$ or $9.0 \mu \mathrm{L}$ of mixed semen. Queen survival was measured through 11 October in 2013 and through 16 October in 2015. A colony was removed from the study if its experimental queen was superseded, if the entire population absconded, or if the colony collapsed prior to any sampling day.

Future studies should be conducted for one or multiple full years to decisively determine if queen insemination volume has a significant effect on colony growth as well as queen supersedure and overwintering survivorship. Queen supersedure, a process that the workers orchestrate when they sense a precipitous drop in queen quality or brood production (Morse and Hooper 1985; Rangel et al. 2013), can reduce overall colony productivity (Kostarelou-Damianidou et al. 1995). Furthermore, because the instrumental insemination procedure itself can alter queen physiology when compared to the amount and type of semen a queen can collect during natural mating (Kocher et al. 2008, 2009, 2010), a longer study comparing the growth of colonies headed by instrumentally inseminated queens versus naturally mated queens would help uncover any parallel effects of insemination volume and the insemination procedure itself on the rate of queen supersedure.

Honey bee queen quality is comprised of a set of complex and interacting traits (Kocher and Grozinger 2011) that are difficult to test independently. Previous studies have shown that queen age (Rangel et al. 2013; Njeru et al. 2017), size (De Souza et al. 2013), nutrition (Fewell and Winston 1992; Njeru et al. 2017), exposure to pesticides (Rangel and Tarpy 2015, 2016), and disease (reviewed in Amiri et al. 2017) affect the productivity of newly established colonies. Although queen insemination volume does not appear to affect most aspects of growth in newly established colonies, perhaps testing the effects of 
queen insemination volume using more genetically uniform colonies (i.e., headed by super-sister queens), in combination with some of these other factors, may help uncover the causes of rapid queen failure and supersedure (one of the biggest issues currently faced by the apiculture industry) observed by beekeepers nationwide (Seitz et al. 2016; Kulhanek et al. 2017).. Understanding how insemination volume affects colony growth and queen survivorship will help us identify mechanisms by which high intra-colonial genetic diversity can be maintained without compromising the survivorship of colonies headed by instrumentally inseminated queens.

\section{ACKNOWLEDGEMENTS}

We would like to thank Susan Cobey for instrumentally inseminating the queens used in this study and Dr. Jane Packard for her help in the statistical analysis of the data. We also thank Lauren Ward, Elizabeth Walsh, and Pierre Lau for their help in data collection.

\section{AUTHORS' CONTRIBUTION}

JR conceived and designed experiments, AP and JR performed experiments, interpreted data, performed analyses and wrote the paper. All authors read and approved the final manuscript.

\section{FUNDING INFORMATION}

This study was funded in part by a USDA-NIFA grant to JR and NI (award 2015-67013-23170) and the Texas AgriLife Research Hatch Project TEX09557. This research was accomplished through support to AP from the Undergraduate Research Scholars Program at Texas A\&M University

\section{COMPLIANCE WITH ETHICAL STANDARDS}

Conflict of interest The authors declare that they have no conflicts of interest.

L'effet du volume d'insémination de la reine sur la croissance des colonies d'abeilles mellifères (Apis mellifera ) nouvellement établies
Apis mellifera / croissance de colonies / insémination instrumentale / volume d'insémination de la reine

Der Effekt des Besamungsvolumens von Königinnen auf die Wachstumsrate neuetablierter Völker der Honigbiene (Apis mellifera)

Apis mellifera / Koloniewachstum / instrumentelle Besamung / Besamungsvolumens von Königinnen

\section{REFERENCES}

Amiri, E., Strand, M. K., Rueppell, O., Tarpy, D. R. (2017) Queen quality and the impact of honey bee diseases on queen health: Potential for nteractions between two major threats to colony health. Insects 8, 48

Baer, B. (2005) Sexual selection in Apis bees. Apidologie 36, 187-200

Cobey, S. W. (2007) Comparison studies of instrumentally inseminated and naturally mated honey bee queens and factors affecting their performance. Apidologie 38, $390-410$

Cobey, S. W., Tarpy, D. R., \& Woyke, J. (2013) Standard methods for instrumental insemination of Apis mellifera queens. J. Api. Res. 52 (4), 1-18

Collins, A. M. (2000) Relationship between semen quality and performance of instrumentally inseminated honey bee queens. Apidologie 31 , 421-429

De Miranda, J. R., Fries, I. (2008) Venereal and vertical transmission of deformed wing virus in honeybees (Apis mellifera L.). J. Invert. Pathol. 98(2), 184-189

De Souza, D. A., Bezzera-Laure, M. A. F., Francoy, T. M., Gonçalves, L. S. (2013) Experimental evaluation of the reproductive quality of Africanized queen bees (Apis mellifera ) on the basis of body weight at emergence. Genet. Mol. Res. 12, 5382-5391. DOI:https://doi. org/10.4238/2013.November.7.13

Fewell, J. H., Winston, M. L. (1992) Colony state and regulation of pollen foraging in the honey bee, Apis mellifera L. Behav. Ecol. Sociobiol. 30 (6), 387-393

Goel, M. K., Khanna, P., Kishore, J. (2010) Understanding survival analysis: Kaplan-Meier estimate. Int. J. Ayurveda Res. 1 (4), 274-278

Harbo, J. R. (1986) Propagation and instrumental insemination, In: Rinderer T.E. (Ed.), Bee Breeding and Genetics. Academic Press, Inc., Orlando, FL. pp. 361-389

Kocher, S., Richard, F. J., Tarpy, D. R., Grozinger, C. M. (2008) Genomic analysis of post-mating changes in the honey bee queen (Apis mellifera). BMC Geno$\operatorname{mics} 9,232$

Kocher, S., Richard, F. J., Tarpy, D. R., Grozinger, C. M. (2009) Queen reproductive state modulates pheromone production and queen-worker interactions in honey bees. Behav. Ecol. 20, 1007-1014 
Kocher, S. D., Ayroles, J. F., Stone, E. A., Grozinger, C. M. (2010) Individual variation in pheromone response correlates with reproductive traits and brain gene expression in worker honey bees. PLoS ONE. https://doi. org/10.1371/journal.pone.0009116

Koeniger, G. (1986) Reproduction and mating behavior, in: Rinderer, T.E. (Ed.), Bee Breeding and Genetics. Academic Press, Inc., Orlando, FL, pp. 235-252

Kostarelou-Damianidou, M., Thrasyvoulou, A., Tselios, D., Bladenopoulos, K. (1995) Brood and honey production of honey bee colonies requeened at various frequencies. J. Api. Res. 34 (1), 9-14

Kulhanek, K., Steinhauer, N., Rennich, K., Caron, D. M., Sagili, R. R., Pettis, J. S., Ellis, J. D., Wilson, M. E., Wilkes, J. T., Tarpy, D. R., Rose, R., Lee, K., Rangel, J., vanEngelsdorp, D. (2017): A national survey of managed honey bee 2015-2016 annual colony losses in the USA. J. Api. Res. https://doi.org/10.1080 /00218839.2017.1344496

Laidlaw, H. H., Page, R. E. (1997) Queen Rearing and Bee Breeding. Wicwas, Cheschire.

Littell, R. C., Henry, P. R., Ammerman, C. B. (1998) Statistical analysis of repeated measures data using SAS procedures. J. Anim. Sci. 76 (4), 1216-1231

Mackensen, O. (1964) Relation of semen volume to success in artificial insemination of queen honey bees. J. Econ. Entomol. 57, 581-583

Mattila, H. R., Seeley, T. D. (2007) Genetic diversity in honey bee colonies enhances productivity and fitness. Science 317 (5836), 362-364

Mitchell, C. (1970) Weights of workers and drones. Am. Bee J. 110, 468-469

Morse, R. A., Hooper, T. (1985) The Illustrated Encyclopedia of Beekeeping. Dutton, New York

Niño, E. L., Malka, O., Hefetz, A., Teal, P., Hayes, J., Grozinger, C. M. (2012) Effects of honey bee (Apis mellifera L.) queen insemination volume on worker behavior and physiology. J. Insect Physiol. 58, 1082-1089

Niño, E. L., Tarpy, D. R.,Grozinger, C. M. (2013) Differential effects of insemination volume and substance on reproductive changes in honey bee queens (Apis mellifera L.). Insect Mol Biol. 22, 233-244

Njeru, L. K., Raina, S. K., Kutima, H. L., Salifu, D., Cham, D. T., Kimani, J. N., Muli, E. M. (2017) Effect of larval age and supplemental feeding on morphometrics and oviposition in honey bee Apis mellifera scutellata queens. J. Apicult. Res. 56 (3), 183-189. DOI: https://doi.org/10.1080/00218839.2017.1307714

Oldroyd, B. P., Fewell, J. H. (2007) Genetic diversity promotes homeostasis in insect colonies. Trends Ecol. Evol. 22 (8), 408-413

Rangel, J., Seeley, T. D. (2012) Colony fissioning in honey bees: size and significance of the swarm fraction. Insect. Soc. 59, 453-462. DOI: https://doi.org/10.1007 /s00040-012-0239-5

Rangel, J., Tarpy, D. R. (2015) The combined effects of miticides on the mating health of honey bee (Apis mellifera L.) queens. J. Apicult. Res. 54 (3), 275-283
Rangel, J., Tarpy, D. R. (2016) In-hive miticides and their effect on queen supersedure and colony growth in the honey bee (Apis mellifera). J. Environ. Anal. Toxicol. 6 :3. DOI: https://doi.org/10.4172/2161-0525.1000377

Rangel, J., Keller, J. J., Tarpy, D. R. (2013) The effects of honey bee (Apis mellifera L.) queen reproductive potential on colony growth. Insect. Soc. 60 (1), 65-73

Richard, F. J., Tarpy, D. R., Grozinger, C. M. (2007) Effects of insemination quantity on honey bee queen physiology. PLoS One. https://doi.org/10.1371/journal. pone. 0000980

Richard F. J., Schal, C., Tarpy, D. R., Grozinger, C. M. (2011) Effects of instrumental insemination and insemination quantity on Dufour's gland chemical profiles and vitellogenin expression in honey bee queens (Apis mellifera ). J. Chem. Ecol. 37, 1027-1036

Seeley, T. D. (1995) The Wisdom of the Hive: The Social Physiology of Honey Bee Colonies. Harvard University Press, Cambridge

Seeley, T. D., Tarpy, D. R. (2007) Queen promiscuity lowers disease within honeybee colonies. Proc. Roy. Soc. Lond. B Biol. Sci. 274 (1606), 67-72

Seeley, T. D., Visscher, P. K. (2003) Choosing a home: how the scouts in a honey bee swarm perceive the completion of their group decision making. Behav. Ecol. Sociobiol. 54, 511-520

Seitz, N., Traynor, K. S., Steinhauer N., Rennich, K., Wilson, M. E., Ellis, J. D., Rose, R., Tarpy, D. R., Sagili, R. R., Caron, D. M., et al. (2016) A national survey of managed honey bee 2014-2015 annual colony losses in the USA. J. Apicult. Res. https://doi.org/10.1080 /00218839.2016.1153294

Tarpy, D. R. (2003) Genetic diversity within honeybee colonies prevents severe infections and promotes colony growth. Proc. Biol. Sci. 270 (1510), 99-103

Tarpy, D. R., Nielsen, D. I. (2002) Sampling error, effective paternity and estimating the genetic structure of honey bee colonies (Hymenoptera: Apidae). Ann. Entomol. Soc. Am. 95, 513-528

Tarpy, D. R., Seeley, T. D. (2006) Lower disease infections in honeybee (Apis mellifera) colonies headed by polyandrous vs monandrous queens. Naturwissenschaften 93 (4), 195-199

Tarpy, D. R., Nielsen, R., Nielsen, D. I. (2004) A scientific note on the revised estimates of effective paternity frequency in Apis . Insect. Soc. 51 (2), 203-204

Wilde, J. (1994) Comparison of the development and productivity of bee colonies with naturally and instrumentally inseminated queens kept in different conditions before and after the insemination. Zootechnica 39, $135-152$

Winston, M. L. (1987) The Biology of the Honey Bee. Harvard University Press, Cambridge

Woyke J. (1989) Results of instrumental insemination, in: Moritz R.F.A. (Ed.), The Instrumental Insemination of the Queen Bee. Bucharest, Apimondia, pp. 93-103 